\title{
The Landmine Project: How to Cross a Fractured Territory
}

\author{
M. R. Prieto, S. Melo, and P. Salas
}

\begin{abstract}
This paper challenges the role technology plays in mediating our landscape experience. In particular, how the underground landmines in the San Pedro de Atacama area in Chile are able to change the way the land is perceived. Promoting a transdisciplinary work, we will address the processes, questions, and contradictions in the production and exhibition of a visual research project.
\end{abstract}

Index Terms-Art, landmines, landscape, technology, territory.

\section{INTRODUCTION}

As young mountaineering enthusiasts, circa 1998, we were planning to climb one of the most imposing mountains in the Atacama Desert: the Licancabur volcano. The Licancabur looks like a perfect cone in the middle of the high plateau; an ubiquitous image of what an Andean landscape is supposed to be (Fig. 1 "The Licancabur"). When planning this trip, we realised that the ancient crossing (the one used by native Aymara shepherds) was interrupted by the presence of landmines. This minefield, invisible to the eye, did not appear on any of the maps of the local area. You were only alerted to its presence once you reached a place by a small red warning sign that read "Peligro Campo Minado, Danger Minefield, Peligrowa Aka Pampa Minatawa" (Fig. 2 Ceilao minefield). We then had to change our plans to climb the volcano across the border, via Bolivia, in order to reach a path on the eastern face of the mountain.

Our plans were disrupted, with only minor consequences. This is not the case for others who live, cross and walk around this area on a daily basis, constantly putting themselves in danger when walking the traditional routes that have allowed people from the high Andes to exchange and meet since ancient times.

Throughout this paper we aim to challenge the role technology plays in mediating our landscape experience and in this particular case, how the underground landmines -objects no bigger than $5 \times 8 \mathrm{~cm}$ - are able to change the way we perceive the land, and play a ubiquitous role in defining its potential. We will reflect upon a recent experience conducted by the Border Agency collective in which we considered the minefields as a singular case of landscape that can only be experienced through a technical media. The Landmine Project attempts to visualise those subject-space-technology

Manuscript received September 20, 2018; revised December 2, 2018 This project was funded by The National Council of Arts CNCA, Chile and it was supported by the National Commission for humanitarian Demining, Chile.

M. R. Prieto and S. Melo are with Goldsmiths University, UK (e-mail: rosario@purodelirio.com, sebastian.melo@gmail.com).

P. Salas is with Faculty of Arts, Pontificia Universidad Católica de Chile, Chile (e-mail: pfsalas@uc.cl). issues that define the perception of contemporary landscape. To investigate this concern we used two strategies of artistic research; the production of a technologically mediated image -using a drone, video and photography - and the creation of an imagined landscape through collective storytelling - using mapmaking, drawing and conversation.

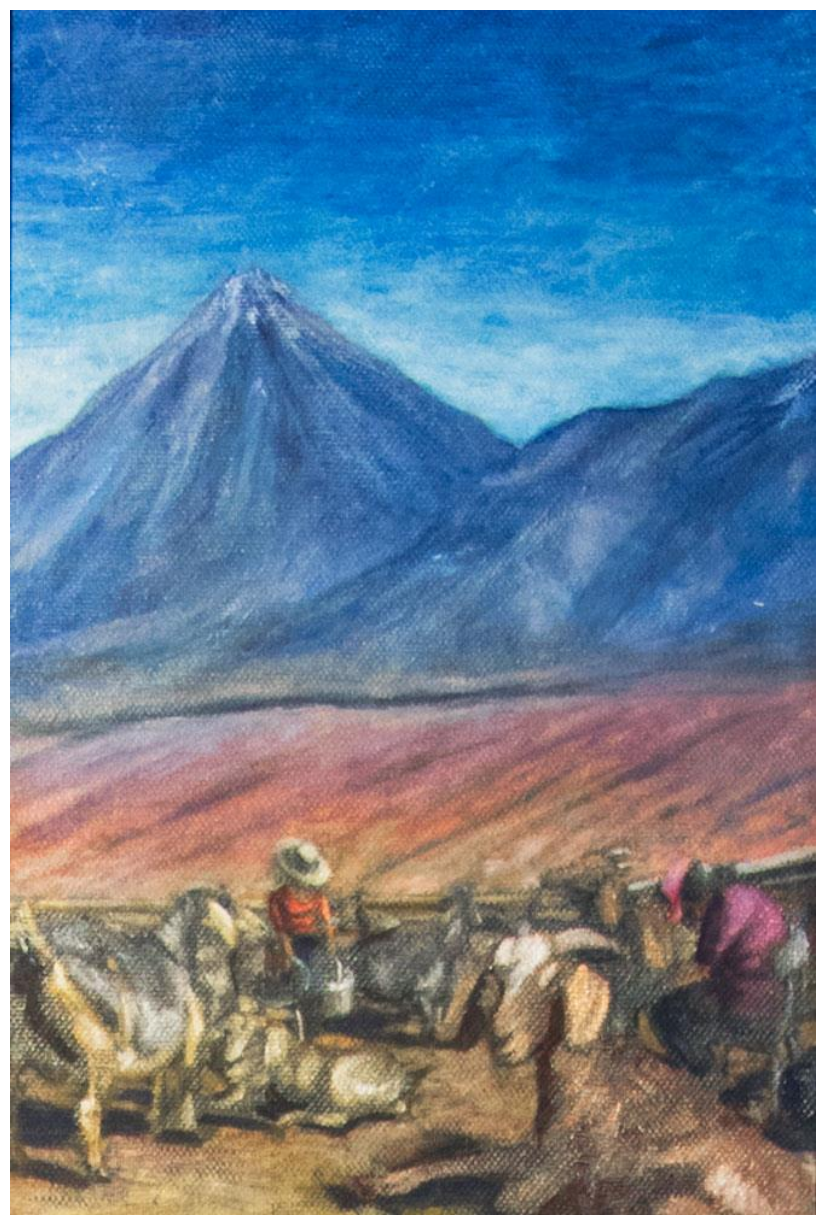

Fig. 1 “The Licancabur", oil painting, $30 \mathrm{~cm}$ by $15 \mathrm{~cm}, 2016$, Border Agency.

We asked ourselves how landscape is culturally constructed, particularly in relation to the minefields at the Atacama Desert. Landscape develops as part of human lives as 'an instrument of cultural power' [1]. Representing a landscape is also a symbolic form of power which, in the long term, creates a reality. As Tilley reveals, landscape representation 'has the potential to both obscure and articulate lived experience' [2]. As W.J.T. Mitchell points out, landscape as a social object, plays a double role in culture. It naturalises the way people relate to their territory 'representing an artificial world as if it were simply given and inevitable and also makes that representation operational by interpellating its beholder' [3]. In this sense, it is fundamental for this research to question the ways in which notions of landscape are shaped, what are the givens for the Chilean 
context, how these representations (landscape paintings, postcards, touristic images, etc.) are operational, and finally the role nature plays in shaping the local concept of landscape. Therefore, through this research, landscape will appear as 'a medium of exchange' [3] where notions are constantly negotiated between the different inhabitants of the land.

\section{CONTEXT}

To provide a historical context, between 1973 and 1983 in Chile, during the military dictatorship more than 181,000 anti-personnel and anti-tank landmines were placed in the border areas of the Regions of Arica and Parinacota, Tarapacá, Antofagasta and Magallanes, in the midst of the crisis with Argentina over the Beagle Canal that almost took Chile to war [4]. The possibility of engaging in a war with Argentina in southern Patagonia, exacerbated existing tensions with Peru and Bolivia which were still lingering from the Pacific War of the nineteenth century. Whilst from the outset, the border landmines were created for defence purposes in the context of military conflicts, their perpetuation has since been justified for controlling the illegal entry of foreigners, contraband, and narcotics [4].

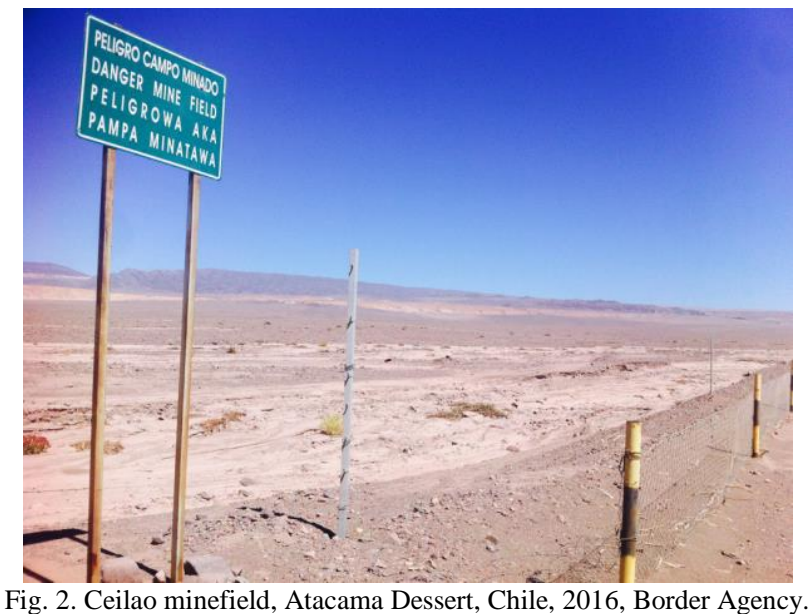

In 1997 Chile signed the Ottawa Treaty during the Convention on the Prohibition of the Use, Stockpiling, Production and Transfer of Anti-Personnel Mines, drawing a plan for the elimination of all anti-personnel landmines (AP-mines) around the world by 2025 . In Chile, more than half of the anti-personnel landmines have been removed, but there are still many more to be eliminated and worse, most of the population are unaware of their presence, particularly those illegal walkers who cross the border without being aware of the risks.

In addition, the geographical conditions of the Atacama Desert have unique features that make their assembly a dynamic explosive landscape [5]. As previously argued, A-P mines are small and very light - most are made from plastic weighing only approximately 100 grams. For its part, the Atacama Desert is a very dynamic and changing territory. The summer rains produce considerable flooding and it is a highly seismic zone. Although the landmines are buried underground, they are not fixed and can move to the arbitrariness of climatic and telluric phenomena [5]. Thus the explosive condition of the landscape changes capriciously and unpredictably.

In this sense, the effect of minefields, from a landscape perspective, is the production of an inaccessible territory which cannot be experienced directly. Anti-personnel mines are a technology that creates virtual borders, a means that divides and radically changes the relationship between the landscape and the inhabited place. With the realisation that we can only have mediated access to the minefields, we have tried to re-appropriate those territories through the use of different mediums. Firstly, the artistic appropriation of a military technology such as drone-filming, detonates a number of ethical problems for media artists. Secondly, the consequences of choosing a militarised zone as a subject for artistic exploration is equally fraught with ethical dilemmas. There are minefields left and right, not least because in Chile, of all places, the issue of militarisation weighs heavily on media cultural imaginaries [6] (Fig. 3 Demining training).

\section{FIELD WORK}

The physical experience of working in the minefields -however cautious we tried to be- put our bodies at risk directly and repeatedly. A fundamental difference between the actual and the represented experience of the minefields is the possibility of suffering in our own flesh the conditions we ourselves were investigating. The experience of danger in these lands becomes evident in many ways and the exhibition's audience might feel the same adrenaline we experienced. The hesitation, embarrassment and fear that such places awaken can be vividly perceived.

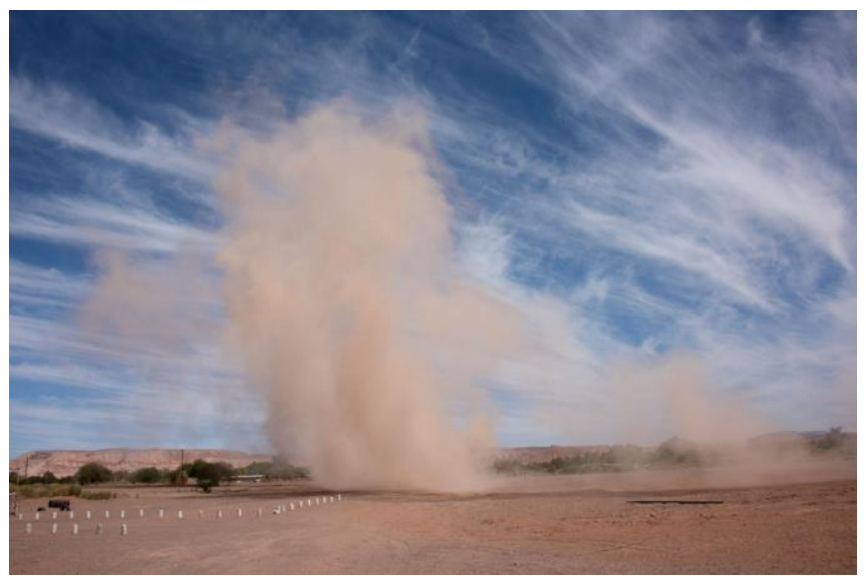

Fig. 3. Demining training, San Pedro de Atacama, Chile, 2016, Border Agency.

We travelled for a week to the San Pedro area to engage with the minefields from multiple perspectives. We used drone cameras to simulate walkthroughs traversing the interior of the minefields, discovering -through the camera eye- only the soil, vegetation and rocks that lie silent above its explosive underground. In one location, at the Huaitiquina pass in the border with Argentina, we witnessed the actual mines as planted more than 30 years ago, still active and uncovered by the wind erosion. We also gained access to the original military maps through which the minefields' location were recorded. These same secret maps - handmade in the 70s and $80 \mathrm{~s}$ - are those used today to find and remove mines from 
the fields. Finally, we interviewed 20 people - both residents and visitors. We talked with a family of pastors, tour guides, foreign tourists, university students, school workers, employees of the municipality, teachers and military staff. They all drew a map depicting the way they navigate the territory, including minefields. We thus constructed a small archive of subjective maps that reveal the intimate everyday side of the minefields and the desert landscape of San Pedro (Fig. 4 Subjective map of the minefields made by local resident).

This desert-mine assembly breaks with the stereotype of the desert landscapes of San Pedro de Atacama as pristine and natural formations similar to Mars, and invites their politicisation as highly contested phenomena, produced under the dynamics of warlike tension and with an explosive ontology. Thus, the Atacama Desert ceases to be understood as a simple territory in dispute, or a potential scenario in which the Chilean army faces the Bolivian or Argentinian force. Under a geopolitical view of the landscape, the Chilean military strategy transformed the Atacama Desert into a weapon-landscape. That is, a desert that explodes when being visited and trampled by its potential victims [7]. Thus, the desert becomes a landscape which, once planted with mines, is capable of protecting itself from becoming a "Bolivian" or "Argentinian" landscape. A landscape-weapon which does not require centrally controlled activation to be triggered by any human, or non-human, weighing as little as 9 to 16 kilos [7].

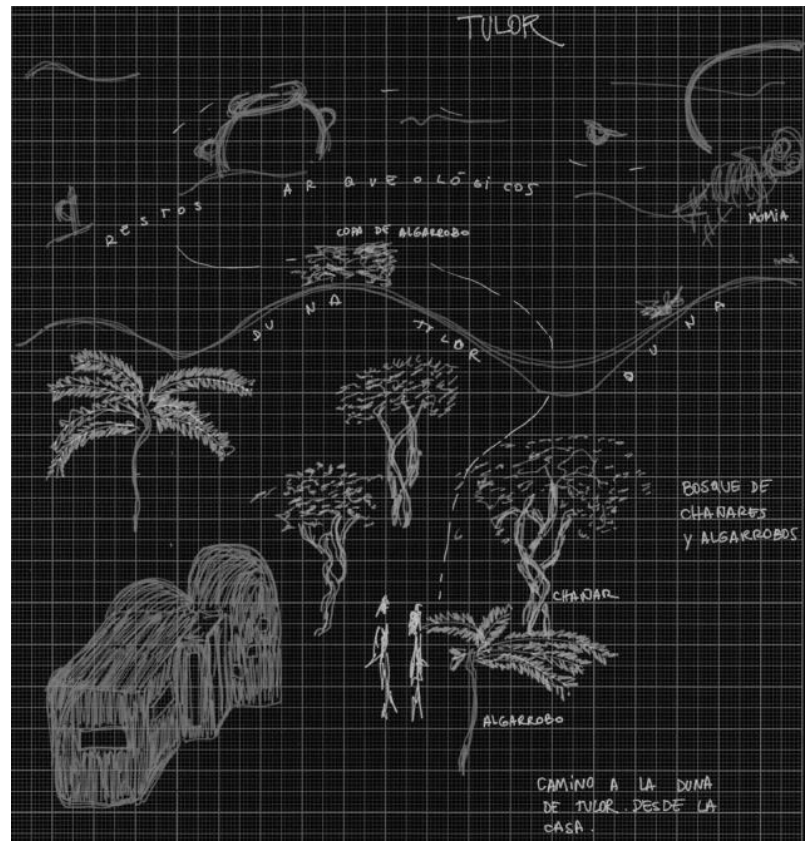

Fig. 4. Subjective map of the minefields made by local resident, San Pedro de Atacama, Chile, 2016, Border Agency.

We engaged with a layered territory of issues and meanings that emphasized the need of a transdisciplinary approach. We installed our work within a crossover between anthropological methodologies and languages specific to the arts. This allowed us to use tools which facilitated the understanding of the dynamics that emerge in the territory and at the same time it gave us the freedom to dislocate these disciplinary methodologies, appropriating them and their discourses.

\section{EXHIBITION}

The title for the exhibition at the Contemporary Art Museum in Santiago (MAC Quinta Normal): "An explosion dull and deep, not too far" refers to an experience, not to a situation or generic problem (such as the mining and demining of the national territory), but to the subjective perception of those who have physically experienced the explosion of a mine. This name already indicates a direction for our investigation, that is the perceptive exploration - how minefields look, how they are heard, how they are felt, how they are traversed. It seemed that any idea about the minefields should emerge from the territory and its inhabitants instead of putting what we knew of the situation or rather what we thought we knew - ahead of the fieldwork.

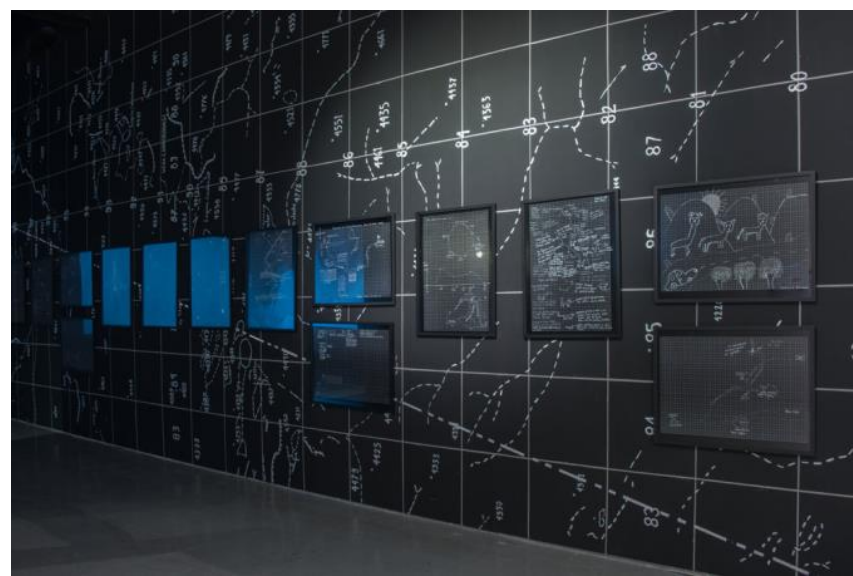

Fig. 5. Exhibition "An explotion deep and dull, not too far...”, Border Agency, Museum of Contemporary Art, Santiago, Chile, 2016.

The exhibition took form as an installation of sound, video, photography and drawing in a dark room where the audience was allowed to enter, listen, see and feel the minefield's multiple representations. But in the actual minefield it is the body itself - its fragility - that prevents you from accessing, treading the ground, and touching it. It is for this reason that we resorted to other devices that would replace our perceptive organs, such as the drone, tape recorder and photo camera to feel/see something vetoed from our bodies. In that sense, the show reproduces the situation we - our bodies - faced within the minefields, that is, the need for representation as the only safe way to perceive those territories. The exhibition enhances the multisensory perception of minefields, but eliminates the bodily risk of direct experience (Fig. 5 Exhibition "An explotion deep and dull, not too far...").

\section{CONCLUSION}

The impossibility of accessing the territory also reveals the duality of observing vs. crossing a territory or, in other words, the image/body division [8]. In order to avoid creating a division between mediated experience and bodily experience, the work brings forth the relationship with the screens and with the materiality of the printed images to imply a certain "crossing". When creating the installation at the Contemporary Art Museum in Santiago and Valdivia, Chile, we were interested in emphasizing the sensorial nature of this aesthetic experience. Despite the sensorial essence of the 
artistic experience we offered in the exhibitions, our audience do not have access to the territory or its index [9], thus the body itself -as the barrier and the vehicle- becomes the central character of the project.

As Nicolas Salazar [10] points out in his collaboration with the project, we (the Border Agency Collective) raise a question: what if accessing the minefield is not only alluding to the hidden explosives planted underground, but to the wider scope of our mediated experience? Salazar turns the questions back on us and, through his reflection, he puts us into conflict by stating:

Experiencing the world through the confines of flat screen media technology is a minefield. Utterly mediated life brings us ever closer to the glorified world of explosion culture. Living glued to a screen enshrines the vision of wondrous balls of fire filling the air-against that flat and depthless shimmer of ubiquitous flatscreen and reel-world, our eyes are becoming orange with the glimmering reflection of exploding things: houses, cars, enemies, and oh, yes, the land itself. [10]

In this sense, Salazar assertions makes us to question that minefields are waiting for us not only in the desert highlands of San Pedro de Atacama, but much closer to home, exploding everyday in front of our eyes as we live inside a media minefield. Impossible to access directly, the experience of media can only be traversed from the periphery, yet it seems to be taken for granted as direct experience. If we are to traverse this media landscape, then let's grab first a metal detector.

The landscape of the Atacama minefields is being constructed by several agents in confronting ways -turned into a weapon by the army, denied by the state, exploited morbidly by the media, pictured exotically by tourist agencies, and experienced daily as an obstacle by local inhabitants. Altogether, our journey from the minefields to the museum, revealed a fluid landscape that escapes any permanent characterization.

\section{ACKNOWLEDGMENT}

Nicolás Melo, Ximena De Luca, Joaquín Cociña, Manuel Melo, Dante Cociña and Dalia Cociña.

\section{REFERENCES}

[1] W. J. T. Mitchell, The Reconfigured Eye: Visual Truth in the Post-Photographic Era, Cambridge, Mass: MIT Press, 1992, p. 2.

[2] C. Y. Tilley, A Phenomenology of Landscape: Places, Paths, and Monuments, Oxford, UK: Berg, 1994, p. 25.

[3] W. J. T. Mitchell, Landscape and Power, Chicago: University of Chicago Press, 1994, p. 2.

[4] D. Holahan. (August 2016). El uso de minas terrestres en Chile. Hacia una teoría de la frontera militar. Revista Civitas [Online]. pp. 343-351. Available:

http://revistaseletronicas.pucrs.br/ojs/index.php/civitas/article/viewFil e/7/6980

[5] M. Prieto. (2016). Los Paisajes Explosivos del Desierto de Atacama. [Online].

Available: http://www.thelandmineproject.com/portfolio/los-paisajes-explosivos -del-desierto-de-atacama/

[6] N. Salazar. (2016). Give Me Explosions. [Online]. Available: http://www.thelandmineproject.com/portfolio-type/textos/

[7] M. Prieto. (2016). Los Paisajes Explosivos del Desierto de Atacama. [Online].

Available: http://www.thelandmineproject.com/portfolio/los-paisajes-explosivos -del-desierto-de-atacama/
[8] N. K. Hayles, How We Became Posthuman: Virtual Bodies in Cybernetics, Literature, and Informatics, Chicago: University of Chicago Press, 1999

[9] C. S. Peirce, "Division of signs," in Collected Papers, 1932.

[10] N. Salazar. (2016). Give Me Explosions. [Online]. Available: http://www.thelandmineproject.com/portfolio-type/textos/

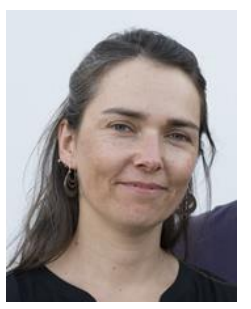

Maria / Rosario Montero (Chile, 1978) is a photo-based artist with a BA (2001, PUC Chile), MFA (2005, University of Chile), a master in digital anthropology (2013, UCL, UK) and recently a PhD in cultural studies (2018, Goldsmiths College, UK).

Maria had his first solo exhibition at the CCE Gallery (Chile) in 2004. She has participated in several group exhibitions in Chile, China, Mexico, Spain, United Kingdom, Peru, USA and Venezuela, among others. Her work is part of the selection of contemporary Chilean photographers for 02 / CNCA (2010) and C Photo edition, "New Latin Look" curated by Martin Parr (2012).

Dr. Montero won several government art funds for the development of his artistic practice (FONDART) in 2010, 2014, 2017, and 2018. Currently, she is involved on a research about the cultural impact of artificial forests in the southern region of Chile and working in a book, and two exhibitions (Chile) related to the representation of landscape in Chile, looking to the indexical character of the photographic image and its colonial instrumentalisation.

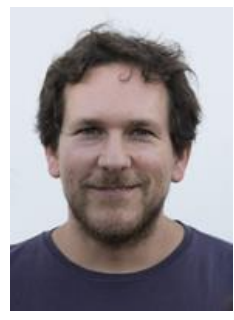

Sebastian Melo (Chile, 1976) received his MA digital media, technology and cultural form at Goldsmiths, University of London (2011, UK) and awarded the Goldsmiths International Postgraduate Scholarship.

Since 2005 he has directed and produced documentary films. His first project "From Afar" was awarded the Grand Prix at the Santiago International Documentary Film Festival (FIDOCS) and distributed by Canal Arte (France). Since 2011 he collaborates with the multidisciplinary project MOVE at Surrey (UK). His video work has been exhibited and awarded in Chile, UK, France, Spain, Canada and Australia among others. Currently, he formed Chaka Studio, developing Quipu a multi-platform interactive documentary project that has been awarded the Tribeca New Media Fund.

Mr. Melo won several government art funds for the development of projects as part of the Border Agency art collective in 2014, 2017, and 2018. Currently, he is involved in a research about the cultural impact of artificial forests in the southern region of Chile.

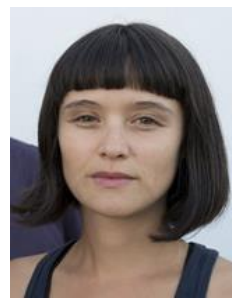

Paula Salas (Chile, 1982) is a visual artist and researcher and teacher. She finished a postgraduate in academic teaching at Pontificia Universidad Católica de Chile 2016. She graduated in 2012 from the Artistic Research MA at the University of Amsterdam, The Netherlands. Previously she studied a BA in fine arts at Pontificia Universidad Católica de Chile 2006, where she also completed a minor in cinema aesthetic, 2005.

Paula has shown her work as artist from 2006 in solo and collective exhibitions in places such as Centro de Arte Contemporáneo de Cerrillos, Santiago, Chile; Gallery D21, Leipzig, Germany, 2017; Museo San Marcos, Lima, Perú 2017, Fjord Gallery, Philadelphia, 2017, USA; Museum of Contemporary Art, Santiago, Chile, 2016; Espai Colona, Barcelona, Spain, 2015; BijlmAIR, Amsterdam, The Netherlands, 2014; Jewett Art Gallery, Wellesley Collegue, Massachusetts, USA, 2014; Upominki, Rotterdam, The Netherlands, 2012; Tropenmuseum, Amsterdam, The Netherlands, 2011.

Ms. Salas has also worked at Universidad Central, Chile, Universidad Gabriela Mistral, Chile and she is currently hired by Pontificia Universidad Católica de Chile. Currently, she is researching the relationship between leisure and productivity in local artistic practices, and she is also conducting a research for Border Agency the cultural impact of artificial forests in the southern region of Chile. 